\title{
Canopy gap edge determination and the importance of gap edges for plant diversity
}

\author{
David Salvador-Van Eysenrode, Fred Kockelbergh, Jan Bogaert, Ivan Impens and Piet Van Hecke
}

\begin{abstract}
Salvador-Van Eysenrode, D., Kockelbergh, F., Bogaert, J., Impens, I. and Van Hecke, P. 2002. Canopy gap edge determination and the importance of gap edges for plant diversity. - Web Ecol. 3: 1-5.
\end{abstract}

\begin{abstract}
Canopy gaps, i.e. openings in the forest cover caused by the fall of structural elements, are considered to be important for the maintenance of diversity and for the forest cycle. A gap can be considered as a young forest patch in the forest matrix, composed of interior surrounded by an edge, both enclosed by a perimeter. Much of the attention has been focused on the gap interior. However, at gap edges the spectrum of regeneration opportunities for plants may be larger than in the interior. Although definitions of gap are still discussed, any definition can describe it in an acceptable way, if justified, but defining edges is complicated and appropriate descriptors should be used. A method to determine gap interior and edge, using light as a descriptor, is presented with an example of gaps from a beech forest (Fagus sylvatica) in Belgium. Also, the relevance and implications of gap edges for plant diversity and calculation of forest turnover is discussed.
\end{abstract}

D. Salvador-Van Eysenrode (davids@uia.ua.ac.be), F. Kockelbergh, J. Bogaert, I. Impens and P. Van Hecke, Research Group of Plant and Vegetation Ecology, Dept of Biology, Univ. of Antwerp (U.I.A.), Universiteitsplein 1, B-2610 Wilrijk, Belgium.

The forest cycle is powered by canopy gaps, which can be considered as forest patches formed by perforation of the forest matrix, due to the fall of the structural elements (Whitmore 1989, Richards 1996, Forman 1997).

In places where gap disturbance occurs, a volume of forest canopy is removed allowing sunlight to reach the understory, and creating free space for plant regeneration. The resulting micro-environmental changes and heterogeneity, the return to a state of competition, and other ecological consequences affect the presence, growth, development and diversity of plants (Grubb 1977, Denslow 1985, 1987, Fagerström 1988, Canham et al. 1990, Hubbell et al. 1999).

Gaps are enclosed by edge zones, which constitute the interface between the gap interior and the surrounding closed forest. As for the gap interior, environmental change is also present at the edge, and this supplies a different and possibly larger spectrum of micro-environmental heterogeneity, because edges are influenced by both the interior and the surrounding habitat (Forman 1997).

These edges can hence be considered as ecotone "rings" (Chen 1991), with characteristic habitat and niche-related opportunities - or conditions - different from the interior and from the closed forest (Forman and Godron 1986, Hansen and Di Castri 1992). Quantifying gap edge width is complicated because the edge boundaries are diffuse. However, because light is the microclimatic variable which shows the greatest contrast between the gaps and the closed forest, it can be used as the discriminant factor to define gap edge width (Reifsnyder and Lull 1965, Chen 1991).

In this paper, we first review two common definitions of gaps, according to Runkle (1981) and Brokaw (1982), further denoted as $A_{R}$ and $A_{B}$ respectively (Fig. 1). Secondly, we show how canopy gaps can be characterized, based 


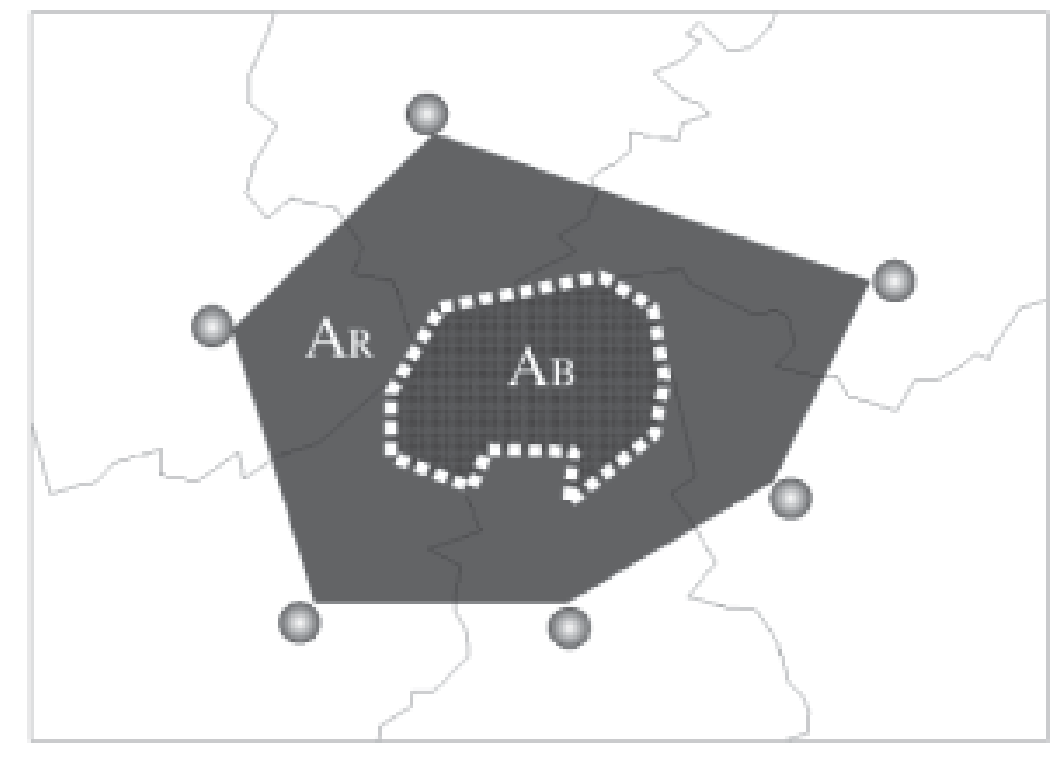

Fig. 1. Illustration of the ground projection of a canopy gap. The area of the vertical projection of the opened canopy $\left(A_{B}\right)$ is found inside the area which extends to the line linking the stems of the surrounding canopy trees $\left(\mathrm{A}_{\mathrm{R}}\right.$; the surrounding tree canopies are represented by the thin lines). Note, however, that $A_{B}$ extends down to two $\mathrm{m}$ above the ground.

\section{Gap $\cap$ Forest canopy $\bigcirc$ Surrounding stems}

on light measurements (the light gap $A_{L}$ ). Thirdly, we define gap edge and interior by matching and combining gap sizes measured as $A_{R}$ and $A_{B}$, and incorporating the size of $A_{L}$. Finally, the effects of different gap definitions on the calculation of the forest turnover are shown and discussed with an example.

\section{Materials and methods}

\section{Gap definitions and area measurement}

For Runkle (1981), a gap is defined as "the ground area under a canopy opening extending to the bases of the surrounding canopy trees". The surrounding trees are usually considered as taller than $10 \mathrm{~m}$, and with a trunk diameter at breast height $\geq 20 \mathrm{~cm}$. Brokaw (1982), in turn, defines a gap as a "hole in the forest canopy extending through all levels down to an average height of two meters above the ground". Other gap definitions are only variants (see Van Der Meer et al. 1994). Minimum gap size and presence of gap maker elements are improvements to define gaps.

Gap size or area (A), regardless of any definition, is generally estimated by tracing a number of radii $(\mathrm{n})$ from a defined gap centroid towards a defined edge point, and adding each area $\left(\mathrm{A}_{\mathrm{i}}\right)$ of the resulting polygons such that

$$
A=\sum_{i=1}^{n} A i
$$

The edge point can be the point of intersection of the vertical ground projection line (at any pre-established height) of the first surrounding tree crowns with the radii (Brokaw 1982), or the intersection of the radii with the lines connecting the trunks of the surrounding trees (Runkle 1981).

As any patch, gaps are composed of an interior area (I), which is surrounded by an edge area (E), the latter enclosed by a perimeter (P) (Forman 1997). Given I and E, the total gap area $\mathrm{A}$ is then

$$
A=I+E
$$

Note that no edge zone is considered in the definitions of $A_{R}$ and $A_{B}$, but only an interior area enclosed by the perimeter, such that

$$
A=I=A_{R} \text { or } A=I=A_{B}
$$

Although defining a gap in the field is complicated, the definitions of Brokaw and Runkle have proven their practical applicability (Van Der Meer et al. 1994). However, considering light as the descriptor of the main change between gaps and closed forest, it is possible to estimate the real gap area $\left(A_{L}\right)$, i.e. the forest area affected by light enhancement such that a gap contrasts with the closed forest.

\section{Study site and measurement of the light gap}

An example is presented with gaps from a beech forest Fagus sylvatica situated south of Brussels (Zonienwoud), $50^{\circ} 46^{\prime} \mathrm{N}, 4^{\circ} 27^{\prime} \mathrm{E}$, altitude ca $120 \mathrm{~m}$, area: 4380 ha (Van Den Berge et al. 1990). We measured $A_{R}$ and $A_{B}$ for 25 selected canopy gaps found at different locations away from the walking trails. $A_{L}$ was measured using a Gap Estimation System (GES, Fig. 2), estimating first a characteris- 
Fig. 2. The Gap Estimation System. The sensor on the tripod $(\mathrm{A})$ is the referential PAR sensor put in the gap center. The remote sensor (B) gives relative light readings from paired synchronic light measurements. The readings are saved in the data-logger for later download to a computer terminal.

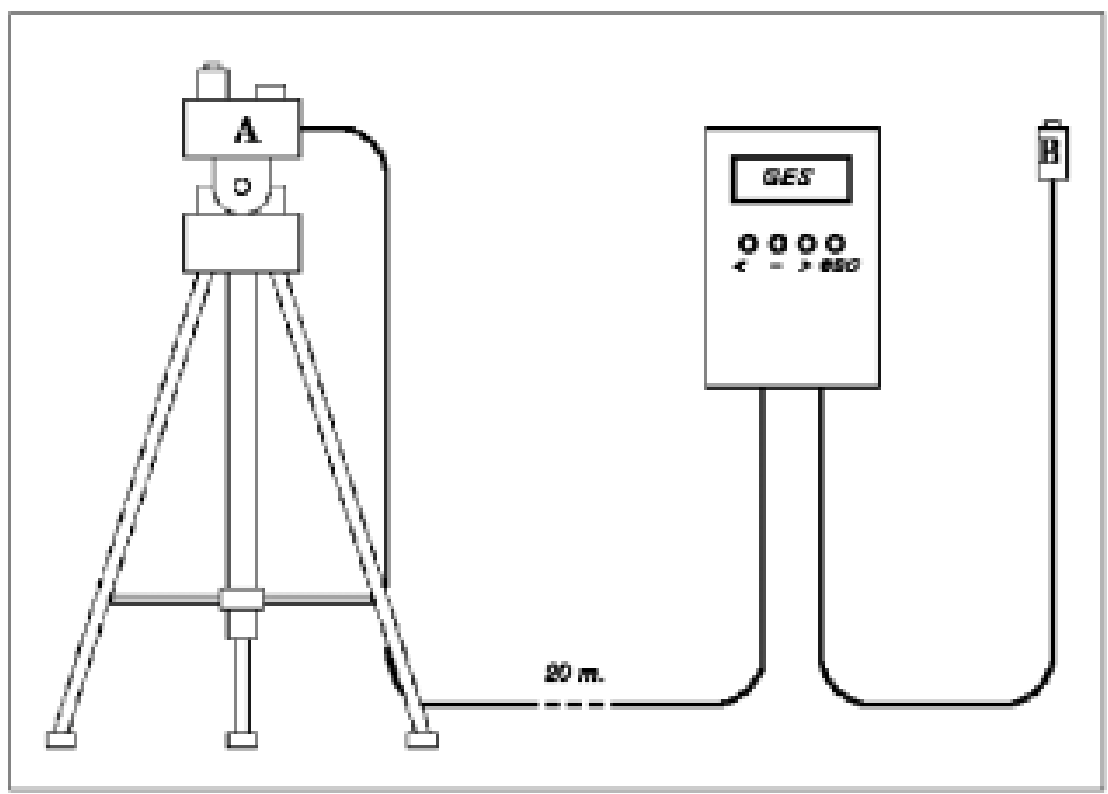

tic average level of light reaching the understory of the closed forest. The light level of the closed forest was determined by averaging one hundred comparative point-measurements of total PAR (photosynthetically active radiation) at random locations between closed forest and an uncovered place (see below).

The average value found $(16.02 \% \pm 9.43 \%)$ was used as a discriminant light level between gaps and closed forest. Secondly, at each meter along the eight radii traced between every gap centroid and the closed forest, we measured total light (PAR) with the GES until the discriminant light level was observed. A line linking the eight edge points was considered and the areas of the resulting octants were added to obtain $A_{L}$. The GES is composed of two light sensors. The first sensor is fixed and referential, and is put above the gap centroid, the place of maximum irradiation. The second sensor is remote and mobile. The GES is designed to measure paired synchronic light levels and generates the percentage of total PAR at each remote point compared with the reference point. This allows comparative light measurements under all sky conditions.

\section{Results}

\section{Gap size distributions}

We found that gap size was normally distributed for both definitions used $\left(A_{R}: K^{2}=0.74 ; A_{B}: K^{2}=0.55\right.$, and $A_{L}: K^{2}=$ 1.85, $\mathrm{p}>0.05$, D'Agostino et al. 1990). The relationship of gap sizes according to the three definitions followed

$$
\mathrm{A}_{\mathrm{B}}<\mathrm{A}_{\mathrm{R}} \approx \mathrm{A}_{\mathrm{L}}
$$

This is evident in Fig. 3. The closeness of $A_{R}$ and $A_{L}$ was expected since shade is already noticeable behind the first trees surrounding gaps and hence both sizes closely match.

\section{Gap edge determination}

From eq. (2), A contains I and E, but the definitions of gap follow eq. (4). However, $A_{B}$ and $A_{R}$ can jointly be used in order to define $E$ considering $I=A_{B}$, since $A_{B}$ is the zone with maximum irradiation. Given the ground projection of $A_{B}$ and $A_{R}$, then

$$
\mathrm{A}_{\mathrm{B}} \subset \mathrm{A}_{\mathrm{R}}
$$

where $\subset$ is the subset property (Fig. 1). From this, E can be defined as

$$
\mathrm{E} \approx \mathrm{A}_{\mathrm{R}}-\mathrm{A}_{\mathrm{B}}
$$

In eq. (6) $E$ is an approximation because $A_{R}$ closely fits with $A_{L}$, the real gap area with ecological relevance. Thus, considering the total gap area $\approx A_{L}$, then

$$
\mathrm{E}=\mathrm{A}_{\mathrm{L}}-\mathrm{A}_{\mathrm{B}}
$$

However, in absence of a method to estimate $A_{L}$, we suggest to use $A_{R}$ and $A_{B}$ to estimate $E$ as in eq. (6). Hereby a gap-patch can be considered completely, i.e. having an interior zone and an edge zone. In the assumption that gaps are circular, then the length of the respective radii (r) are given by

$$
r_{R}=\sqrt{\frac{A_{R}}{\pi}} \text { and } r_{R}=\sqrt{\frac{A_{B}}{\pi}}
$$

where $r_{B}<r_{R}$. With both radii, it is possible to estimate the 

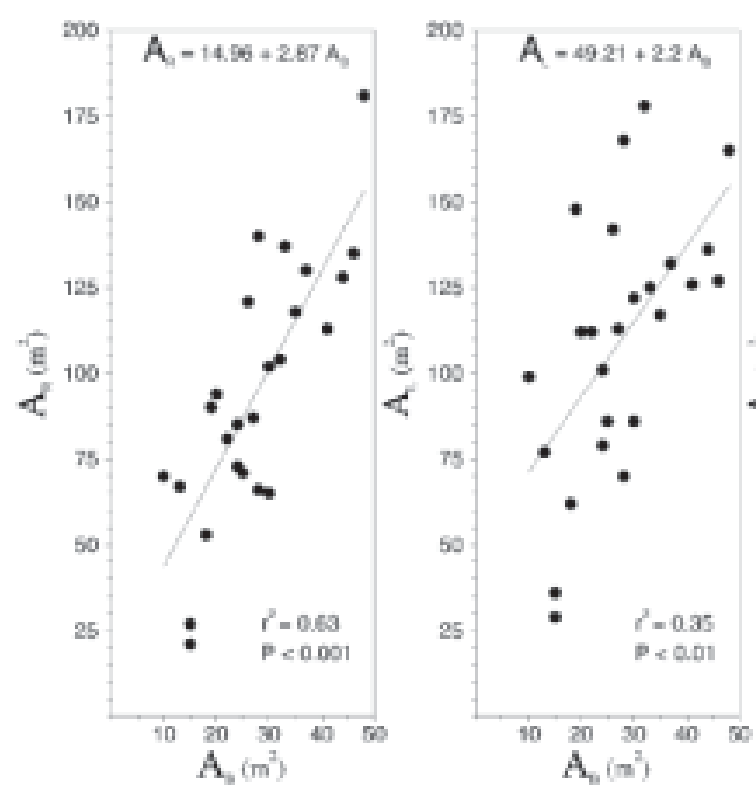

penetration depth $\mathrm{d}$ or width of the edge zone, i.e. the distance between the limits of $A_{B}$ and $A_{R}$ :

$$
\mathrm{d}=\mathrm{r}_{\mathrm{R}}-\mathrm{r}_{\mathrm{B}}
$$

This gives: $\overline{\mathrm{x}} \mathrm{r}_{R}=5.36 \pm 1.13 \mathrm{~m}, \overline{\mathrm{x}} \mathrm{r}_{\mathrm{B}}=2.91 \pm 0.55 \mathrm{~m}$, and a mean $\mathrm{d}$ of $2.44 \pm 0.79 \mathrm{~m}$, indicating that the mean width of the edge zone of a gap is almost as long as (84\%) the mean radius of the interior zone.

Figuer 3 shows how $A_{B}$ and $A_{R}$ determine the other definitions of gap. For the regression of $A_{B}$ and $A_{R}$, when the intercept equals 0 , then $A_{R} \approx 15 \mathrm{~m}^{2}$. This is a consequence of the canopy diameters of the surrounding trees. Therefore, a minimum gap size should be considered in the definition of gap. In the regression of $A_{B}$ with $A_{L}, r^{2}$ is lower because of the irregularity of the gap opening itself and variation in surrounding canopy height, hence allowing light to be projected sometimes further away - or nearer from the canopy opening into the closed forest.

\section{The use of gap definitions to estimate forest turnover}

Assume that the cumulative area of the 25 gaps (sensu Brokaw) represents a hypothetical yearly $1 \%$ of a plot area of 6.9 ha. The forest turnover time $t_{1}$ (i.e. number of years necessary to cover the whole forest area with gaps, Hartshorn 1978) or the stand half life $t_{0.5}$ (i.e. time needed to cover one half of the forest area with gaps, Riéra and Alexandre 1988) can be used to assess the area of forest affected by gaps during the forest cycle, i.e.

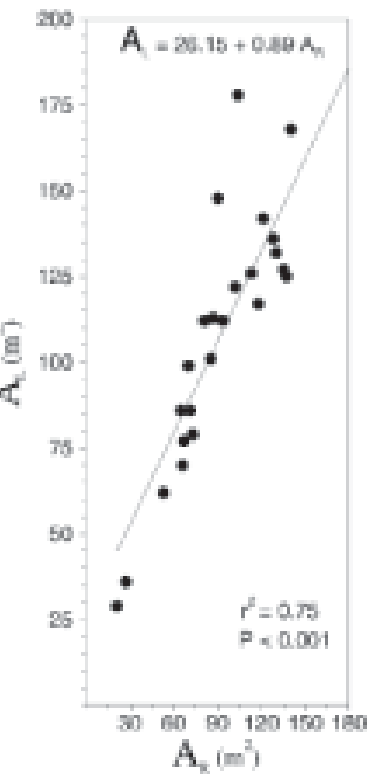

Fig. 3. Regression between the areas of Brokaw $\left(A_{B}\right)$, Runkle $\left(A_{R}\right)$ and real gap area affected by light enhancement $\left(A_{L}\right)$. $A_{R}$ and $A_{L}$ are the closest together. Data from a beech forest (Zoniënwoud) south of Brussels.

$$
\mathrm{t}_{1}=\frac{1}{\alpha} \text { and } \mathrm{t}_{0.5}=\frac{-\ln [0.5]}{\alpha}
$$

where $\mathrm{a}$ is the annual cumulative area of new gaps as a fraction of the forest area (unity). The stand half life is sometimes preferred because it is more realistic: it buffers the condition of linearity as assumed by the turnover time.

Table 1 summarizes the respective values of $t_{1}$ and $t_{0.5}$ when using $A_{R}, A_{B}$ and $A_{L}$. Using $A_{R}$ and $A_{L}$ will result in a $t_{1}$ of 3.4-4 times faster than with $A_{B}$, and roughly the same proportions are found when using $t_{0.5}$. This suggests that an opening in the canopy will influence ca 3.5-4 times more area in the understory, considering either the extended gap area $\left(A_{R}\right)$ or the real area affected by light enhancement $\left(A_{L}\right)$.

Since the forest of the dataset is a plantation, with roughly the same stand age and practically one single tree species, considerable homogeneity is present in the measurements. However, similar results are expected in other old-growth forests with heterogeneous conditions and a

Table 1. Linear turnover time $\left(t_{1}\right)$ and stand half life $\left(t_{0.5}\right)$ for two definitions of gap and the light gap area. The light gap area and $A_{R}$ include the interior and the edge zones of the gap. Assumed forest area $=6.9$ ha.

\begin{tabular}{lrl}
\hline & $\mathrm{t}_{1}(\mathrm{yr})$ & $\mathrm{t}_{0.5}(\mathrm{yr})$ \\
\hline $\mathrm{A}_{\mathrm{B}}$ & 100.00 & 69.30 \\
$\mathrm{~A}_{\mathrm{R}}$ & 29.30 & 20.03 \\
$\mathrm{~A}_{\mathrm{L}}$ & 25.12 & 17.7 \\
\hline
\end{tabular}


relatively closed forest canopy: the relative effect of light enhancement will always go as deep into the closed forest until it hits the first obstacles.

\section{Conclusions}

We have shown that the gap area (at the floor) affected by light enhancement is similar to the area as defined by Runkle (1981). Because a larger interior area is considered, gap area sensu Runkle implies that gaps have larger perimeters than when using the area sensu Brokaw (Forman and Godron 1986). The gap edge area, as defined in this paper, may supply more habitat, and niche-related opportunities for the plants already established before gaps are formed and for the potential recruiting vegetation (Ricklefs 1976, Grubb 1977). For instance, our method to define gap interior and edge assumes constant illumination of the gap, i.e. the seasonal variation of the sunlight regime is neglected on purpose; therefore, this method should be considered in general.

The estimated forest area affected by gaps, and hence turnover time, are also influenced by the use of different definitions of gap. The gap area of Runkle influences up to four times more area of forest than Brokaw's gap area.

We suggest using $A_{R}$ when calculating the turnover time or the forest area affected by gaps, since gap size following this definition is close to the real gap area affected by light enhancement. However, if discrimination between the gap interior zone and the edge zone is required, we suggest to use the combination of definitions here presented. Future research should focus on the differences in structure and composition, and vegetative responses of plants between the gap interior and gap edge.

\section{References}

Brokaw, N. V. L. 1982. The definition of tree-fall gap and its effect on measures of forest dynamics. - Biotropica 14: 158160.

Canham, C. D. et al. 1990. Light regimes beneath closed canopies and tree-fall gaps in temperate and tropical forests. Can. J. For. Res. 20: 620-631.

Chen, J. 1991. Edge effects: microclimatic pattern and biological responses in old-growth Douglas-fir forests. - Ph.D. thesis, Univ. of Washington.
D’Agostino, R. B., Belanger, A. and D’Agostino, R. B. Jr 1990. A suggestion for using powerful and informative tests of normality. - Am. Stat. 44: 316-321.

Denslow, J. S. 1985. Disturbance-mediated coexistence of species. - In: Pickett, S. T. A. and White, P. S. (eds), The ecology of natural disturbance and patch dynamics. Academic Press, pp. 307-323.

Denslow, J. S. 1987. Tropical rainforest gaps and tree species diversity. - Ann. Rev. Ecol. Syst. 18: 431-451.

Fagerström, T. 1988. Lotteries in communities of sessile organisms. - Trends Ecol. Evol. 40: 303-306.

Forman, R. T. T. 1997. Land mosaics, the ecology of landscapes and regions. - Cambridge Univ. Press.

Forman, R. T. T. and Godron, M. 1986. Landscape ecology. Wiley.

Grubb, P. J. 1977. The maintenance of species-richness in plant communities: the importance of the regeneration niche. Biol. Rev. 52: 107-145.

Hansen, A. J. and di Castri, F. 1992. Landscape boundaries, consequences for biotic diversity and ecological flows. - Springer.

Hartshorn, G. S. 1978. Tree falls and tropical forest dynamics. In: Tomlinson, P. B. and Zimmermann, M. H. (eds), Tropical trees as living systems. Cambridge Univ. Press, pp. 637638.

Hubbell, S. P. et al. 1999. Light-gap disturbances, recruitment limitation, and tree diversity in a neotropical forest. - Science 283: 554-557.

Reifsnyder, W. E. and Lull, H. W. 1965. Radiant energy in relation to forests. - Tech. Bull. No. 1344, U.S. Dept of Agriculture, Forest Service.

Richards, P. W. 1996. The tropical rainforest. - Cambridge Univ. Press,

Ricklefs, R. E. 1976. Environmental heterogeneity and plant species diversity: a hypothesis. - Am. Nat. 111: 376-381.

Riéra, B. and Alexandre, D. Y. 1988. Surface des chablis et temps de renouvellement en forêt dense tropicale. - Acta Oecol. 9: 211-219.

Runkle, J. R. 1981. Gap regeneration in some old-growth forests of the eastern United States. - Ecology 62: 1041-1051.

Van Den Berge, K. et al. 1990. Analysis of a forest reserve in a 215-year stand in the Zoniënwoud. - Rep. \#17, Ministerie van de Vlaamse Gemeenschap, Dienst Groen, Waters en Bossen, in Dutch.

Van Der Meer, P. J. et al. 1994. Defining canopy gaps in a tropical rain forest: effects on gap size and turnover rates. - Acta Oecol. 15: 701-714.

Whitmore, T. C. 1989. Canopy gaps and the two major groups of forest trees. - Ecology 70: 563-538. 